\title{
Exploring the Health Informatics Occupational Group in the 2018 Australian Health Information Workforce Census
}

\author{
Kerryn BUTLER-HENDERSON ${ }^{\mathrm{a}}$, Kathleen GRAY ${ }^{\mathrm{b}}$, Christopher PEARCE $^{\mathrm{c}}$, \\ Ann RITCHIE ${ }^{\mathrm{d}}$, Julie BROPHY ${ }^{\mathrm{e}}$, Louise K SCHAPER ${ }^{\mathrm{f}}$, Vicki BENNETT ${ }^{\mathrm{g}}$, \\ and Angela RYAN ${ }^{\mathrm{h}}$ \\ ${ }^{\mathrm{a} C o l l e g e}$ of Health and Medicine, University of Tasmania, Launceston, Tasmania, \\ Australia \\ ${ }^{\mathrm{b}}$ Health and Biomedical Informatics Centre, The University of Melbourne, \\ Parkville, Victoria, Australia \\ ${ }^{\mathrm{c}}$ Australasian College of Health Informatics, Melbourne, Victoria, Australia \\ d Australian Library and Information Association Health Libraries Australia, \\ Melbourne, Victoria, Australia \\ ${ }^{\mathrm{e}}$ Workforce Branch Strategy and Planning, Victorian Department of Health and \\ Human Services, Melbourne, Victoria, Australia \\ ${ }^{\mathrm{f}}$ Health Informatics Society of Australia, Melbourne, Victoria, Australia \\ ${ }^{\mathrm{g}}$ Health Information Management Association of Australia, North Ryde, New South \\ Wales, Australia \\ h Australian Digital Health Agency, Sydney, New South Wales, Australia
}

\begin{abstract}
There has been no empirical evidence about the health informatics workforce in Australia produced in the last ten years. This study reports the findings from an analysis of a subset of the 2018 Australian Health Informatics Workforce Census data. Analysing 420 responses that were identified as the occupational group Health Informatics, the results indicate that whilst most of the workforce is classified as aged ( $\geq 45$ years), many respondents are still relatively early in their health informatics careers. Furthermore, most do not possess any formal education in health informatics and almost a quarter undertake their health informatics role alongside another health-related role. The broad range of position titles and functions demonstrates the breadth within this workforce. Ongoing monitoring of this occupational group is required to inform workforce reform and renewal.
\end{abstract}

Keywords. Health informatics, workforce, census

\section{Introduction}

Health Informatics (HI) is a nascent profession, and a detailed understanding of the workforce is lacking. In 2009 Legg and Lovelock [1] published a seminal report examining the Australian HI workforce. They provided several insights into this occupational area that long has been in the shadows. Whilst there have been several studies [2-4] across other areas of the Australian health information workforce in the ten years since, there has not been another HI workforce study. While the field is rapidly 
evolving, in the absence of empirical data, there is only anecdotal information on how the workforce has changed since 2009.

Several subsequent papers [5-8] have called for the ongoing monitoring of the HI workforce, with Health Workforce Australia (2013) recommending the delineation of the workforce and improved data collection [5]. This was supported by the 2016 National Health Information Workforce Summit agreed action plan and a workforce focus group [6-7]. The development of the Australian Health Information Workforce Census tool was presented at the 2017 Health Informatics Conference (HIC) [8], with the first census held across Australia in May 2018. This paper reports the findings from the analysis of the subset of data from this census defined as the occupational group Health Informatics.

\section{Methods}

The 2018 Australian Health Information Workforce Census invited participants who self-identified as part of the health information workforce who "work (including volunteer or actively seeking) in a role where the primary function is related to developing, maintaining, or governing the systems for the management of health data, health information, or health knowledge... for/with an organisation that operates in Australia, your role relates to the Australian operations, and relates to the health sector" [9]. Participants completed the Australian Census online during May 2018, with consent captured at the start of the census. The Census Management Group of experts concluded that it was a representative sample when compared to past Australian studies [2-4], and estimated that it captures an approximate $20 \%$ sample size [10].

To identify those who are part of the HI occupational group, the following eligibility criteria were used to extract relevant responses. Responses were included where they either:

1. Identified as [Health informatician] OR [Health information technology specialist] or [Data analyst] to the question "If you could classify this occupation, in which of the following occupation categories would you classify your health information occupation?"; OR

2. Responded [Unable to classify] or [None of the above] to the above question BUT specified they are a Fellow/Member of [Australasian College of Health Informatics (ACHI)], [Australasian Health \& Research Data Managers Association (AHRDMA)], [Australian Computer Society (ACS)], [Health Informatics New Zealand (HiNZ)], [Health Informatics Society of Australia (HISA)], [Healthcare Information and Management Systems Society (HIMSS)], [Institute of Analytics Professionals of Australia (IAPA)], [Medical Software Industry Association (MSIA)], OR [Records \& Information Management Professionals Australasia (RIM)]; OR

3. Responded [Unable to classify] or [None of the above] to question 1 above AND specified [Other relevant health information professional organisation] to question 2 above, BUT specified a relevant health informatics organisation (e.g. HL7).

Responses were excluded if they identified as another distinct occupational group [Clinical coder], [Costing analyst], [Health information manager] OR [Health librarian] - in question 1 above. Eligible responses were extracted from the census database into an MS Excel spreadsheet and imported into IBM ${ }^{\circledR}$ SPSS v25.0 for analysis. 
Ethical approval was obtained from the University of Tasmania Social Science Human Research Ethics Committee (\#H0017281) and a privacy statement and Data Management and Access Policy are available on the census website.

\section{Results}

A total of 420 respondents to the 2018 Health Information Workforce Census met the aforementioned eligibility criteria and are included in these results. Of these, $415(98.8 \%)$ currently reside in Australia, with the remainder are servicing the Australian health industry while residing in New Zealand, Europe, or the United States. Over half (58.1\%) of respondents identified as female. The average age was 45.4 years (range 21-73 years). $23.9 \%(99 / 420)$ of respondents identified as a registered health practitioner under the National Regulation and Accreditation Scheme (nurses, doctors, allied health, etc). When asked about specific health information/informatics educational qualifications, $73.1 \%$ stated they do not hold any relevant qualification.

The characteristics of the occupational group health informatics are summarised in Tables 1 and 2 . The majority $(51.4 \%)$ of respondents had $\leq 10$ years' experience in HI, reflecting a relatively early-career workforce. Furthermore, $63.6 \%$ of respondents had been in their current role for $\leq 5$ years, reflecting the transient nature of the workforce. Over two-thirds (69.4\%) of respondents worked for a public organisation, $41.5 \%$ being in a hospital.

Table 1. Employment and organisational characteristics

\begin{tabular}{|c|c|c|c|}
\hline $\begin{array}{l}\text { Employment } \\
\text { Characteristic }\end{array}$ & Responses & Number (n) & Percentage \\
\hline \multirow{2}{*}{$\begin{array}{l}\text { Years of experience in } \\
\text { HI } \\
(n=420)\end{array}$} & In Australia & \multirow{2}{*}{\multicolumn{2}{|c|}{$\begin{array}{l}\text { Average } 13.3 \text { years } \\
\text { (Range } 1-47 \text { years) } \\
\text { Average } 12.5 \text { years } \\
\text { (Range } 1-47 \text { years) }\end{array}$}} \\
\hline & Total & & \\
\hline \multirow{6}{*}{$\begin{array}{l}\text { Major } \quad \text { employment } \\
\text { group } \\
(n=420)\end{array}$} & Professional & 243 & $57.9 \%$ \\
\hline & Manager & 107 & $25.5 \%$ \\
\hline & Clerical or Administrative Worker & 38 & $9.0 \%$ \\
\hline & Unable to classify & 20 & $4.8 \%$ \\
\hline & Technician or Trades Worker & 7 & $1.7 \%$ \\
\hline & Sales Worker & 5 & $1.2 \%$ \\
\hline \multirow{5}{*}{$\begin{array}{l}\text { Current in paid } \\
\text { employment } \\
(\mathrm{n}=420)\end{array}$} & Health informatics role & 289 & $68.8 \%$ \\
\hline & Health informatics role \& another health role & 87 & $20.7 \%$ \\
\hline & Another health role & 23 & $5.5 \%$ \\
\hline & Non-health role & 7 & $1.7 \%$ \\
\hline & Not currently in paid employment & 14 & $3.3 \%$ \\
\hline \multirow{9}{*}{$\begin{array}{l}\text { State/Territory } \\
(n=376)\end{array}$} & Victoria & 135 & $35.9 \%$ \\
\hline & New South Wales & 95 & $25.3 \%$ \\
\hline & Queensland & 61 & $16.2 \%$ \\
\hline & Tasmania & 27 & $7.2 \%$ \\
\hline & Australian Capital Territory & 20 & $5.3 \%$ \\
\hline & Western Australia & 18 & $4.8 \%$ \\
\hline & South Australia & 16 & $4.3 \%$ \\
\hline & Northern Territory & $<5$ & - \\
\hline & Multiple states & $<5$ & - \\
\hline \multirow{4}{*}{$\begin{array}{l}\text { Organisation Status } \\
(\mathrm{n}=376)\end{array}$} & Public & 261 & $69.4 \%$ \\
\hline & Private & 64 & $17.0 \%$ \\
\hline & Public/Private partnership & 11 & $2.9 \%$ \\
\hline & Not for Profit & 40 & $10.6 \%$ \\
\hline Organisation Type & Hospital & 156 & $41.5 \%$ \\
\hline
\end{tabular}


$(n=376)$

State health department
Health technology organisation
Local health service
Federal health organisation
Primary care or primary health network
Other public/government organisation
Educational facility
Other private organisation
Other not for profit organisation
Community health care service
Insurance organisation
Residential health care facility
Indigenous health service
Correctional services

44

The average weekly hours were reported as 33.5 hours. These part-time hours may be due to several reasons, including respondents working multiple roles. Of the $89.5 \%$ (376) of respondents who are currently working in a HI role, nearly a quarter (23.1\%) also work in another health role (for example, clinical or administrative role). A further $5.9 \%$ of respondents reported working in two or more $\mathrm{HI}$ roles.

Table 2. Health informatician characteristics

\begin{tabular}{|c|c|c|c|}
\hline Characteristic $(n=376)$ & Responses & Number (n) & Percentage \\
\hline \multirow{4}{*}{ Employment Status } & Permanent & 256 & $67.7 \%$ \\
\hline & Contract & 102 & $27.0 \%$ \\
\hline & Casual & 10 & $2.6 \%$ \\
\hline & Self-employed & 10 & $2.6 \%$ \\
\hline Years in current primary & $<5$ years & 239 & $63.6 \%$ \\
\hline \multirow[t]{5}{*}{ Health Informatics role } & $5-9$ years & 80 & $21.3 \%$ \\
\hline & 10-14 years & 23 & $6.1 \%$ \\
\hline & $15-19$ & 21 & $5.6 \%$ \\
\hline & $21-24$ & $<5$ & - \\
\hline & $\geq 25$ & 9 & $2.4 \%$ \\
\hline \multirow[t]{2}{*}{ Weekly hours worked } & Paid hours & \multirow{2}{*}{\multicolumn{2}{|c|}{$\begin{array}{l}\text { Average } 33.5 \text { hours } \\
\text { (Range } 2-75 \text { hours) } \\
\text { Average } 35.7 \text { hours } \\
\text { (Range } 2-82 \text { hours) }\end{array}$}} \\
\hline & Actual hours worked & & \\
\hline \multirow{7}{*}{$\begin{array}{l}\text { Weekly wage before tax } \\
(n=320)\end{array}$} & $<\$ 1000$ & 31 & $9.7 \%$ \\
\hline & $\$ 1000-\$ 1449$ & 61 & $19.1 \%$ \\
\hline & $\$ 1500-\$ 1999$ & 79 & $24.7 \%$ \\
\hline & $\$ 2000-\$ 2499$ & 58 & $18.1 \%$ \\
\hline & $\$ 2500-\$ 2999$ & 37 & $11.6 \%$ \\
\hline & $\$ 3000-\$ 3499$ & 14 & $4.4 \%$ \\
\hline & $\geq \$ 3500$ & 40 & $12.5 \%$ \\
\hline \multirow{3}{*}{$\begin{array}{l}\text { Number of respondents } \\
\text { with current Health } \\
\text { Informatics role/s }\end{array}$} & 1 health information role & 354 & $94.1 \%$ \\
\hline & 2 health information roles & 19 & $5.1 \%$ \\
\hline & 3 health information roles & $<5$ & - \\
\hline
\end{tabular}

Health informaticians work across a wide range of roles, with 310 different role titles reported by respondents. The most common titles reported by $25.8 \%$ of respondents included: (Clinical) Business Analyst, Chief Clinical Information Officer, Chief Data Scientist, Chief Medical Information Officer, Chief Nursing Information Officer, Clinical Application Specialist, Clinical Informaticist, Clinical Informatics Manager, Consultant, Data Analyst, Data Manager, Digital Health Manager, Digital Health Officer, Director, EMR Analyst, Enterprise Architect, Health Information Manager, Health Information Officer, Implementation Consultant, Project Manager, and Research Fellow. 
The census captured the top five functions of the current primary HI role of respondents. These were thematically analysed, as shown in Table 3, into the themes:

a). People: functions that impact people;

b). Process: the process to complete a function;

c). Outputs: what the function produces.

The top three People functions are to "Assist", "Manage" and "Educate" people. This shows the role of a health informatician is collaborative and often team based. There were 136 different terms used to describe Process, with the top 20 most commonly used terms reported in Table 3. The top three, "Manage", "Develop" and "Design" again demonstrate the collaborative nature of HI, and the broad range of functions within the discipline of HI. This is supported by the range of knowledge areas identified by respondents. Mapped against the Certified Health Informatician Australasia (CHIA) knowledge domains [11], respondents identified those they apply in their role: Health and Biomedical Science (165, 40.5\%); Human and Social Science (164, 40.3\%); Information and Communication Technology (280, 68.8\%); Data and Information Science (275, 67.6\%); Management Science (221, 54.3\%). Lastly, the majority of respondents identified their Outputs related to "Data", with the top five areas within Outputs reported as "Data", "Technology", "Data analysis", "Data Presentation" and "System".

Table 3. Job function themes (People, Process, Output)

\begin{tabular}{|c|c|c|c|c|c|}
\hline People & Number & Process & Number & Output & Number \\
\hline Assist & 78 & Manage & 126 & Data & 196 \\
\hline Manage & 75 & Develop & 61 & Technology & 86 \\
\hline Educate & 58 & Design & 28 & Data analysis & 86 \\
\hline Collaborate & 37 & Research & 28 & Data Presentation & 63 \\
\hline Advise & 32 & Standardise & 23 & System & 53 \\
\hline Plan & 31 & Maintain & 19 & Governance & 35 \\
\hline Engage & 25 & Test & 19 & Finance & 21 \\
\hline Lead & 22 & Classify & 17 & Safety & 20 \\
\hline Coordinate & 14 & Review & 17 & Data Storage & 18 \\
\hline \multirow[t]{9}{*}{ Advocate } & 8 & Govern & 14 & Terminology & 6 \\
\hline & & Prepare & 14 & Information Services & 5 \\
\hline & & Audit & 13 & & \\
\hline & & Change & 13 & & \\
\hline & & Implement & 13 & & \\
\hline & & Program & 13 & & \\
\hline & & Check & 11 & & \\
\hline & & Extract & 11 & & \\
\hline & & Plan & 11 & & \\
\hline
\end{tabular}




\section{Discussion}

$\mathrm{HI}$ is still a relatively widely defined occupation that is evolving as rapidly as the system it services. Given that it is an older population (45.4 years) compared to the average Australian working age of 39.8 years [12], and the lack of a formal career path and educational qualifications requirements, it may be difficult to explain to new entrants to the profession what career development steps are important. Furthermore, over a quarter of the workforce works in more than one role, with a lower number of respondents working full time hours $(55.9 \%)$ than the national average $(60.2 \%)$. These factors all have intergenerational implications for the workforce.

The majority reported a professional level wage, with $71.2 \%$ reporting an average weekly wage of $\geq \$ 1500$ compared to the national average weekly wage of $\$ 1,288.70$ [12]. 83.4\% identified their occupational group as professional or manager. Yet health informatics is not a recognised health profession in the Australian and New Zealand Standard Classification of Occupations (ANZSCO) and there is a lack of formal education requirements placed on people holding existing or new HI roles. Until educational requirements are addressed, the argument to be recognised as a health profession in the ANZSCO will be a difficult one to make. Furthermore, the large number of role titles demonstrates not only the breadth of roles in the HI workforce and therefore the broad knowledge base a health informatician requires, but the lack of standardisation in role titles across the sector. The findings from the analysis of role functions will assist with future role development and specification.

These findings provide a basis for HI peak bodies to advocate for more opportunities for health informaticians outside of the tertiary healthcare system - for example in public health, in primary and community health, in aged care and in the related policy and service sectors. Whilst small pockets exist outside hospitals, closing the current occupational gaps elsewhere may contribute to closing the information gaps among health organisations and will demonstrate a commitment to a better connected healthcare system overall.

It is acknowledged that the findings in this paper are based on the first national census, which represented approximately $20 \%$ of the workforce. In particular, the census reported a large proportion of respondents working in Victoria, New South Wales, and Queensland, which may be skewed due to the recruitment strategy instead of the actual national workforce representation. Therefore, these findings may be indicative rather than definitive.

It is recommended that the ongoing monitoring of this occupational group through the analysis of future census data be undertaken to accurately capture evidence about the HI workforce. This will support health workforce planning, policy and strategy, and enable us to reform and renew the workforce to support the safe delivery of patient care in Australia.

\section{References}

[1] M. Legg \& B. Lovelock, A review of the Australian health informatics workforce, Health Informatics Society of Australia, Melbourne, 2009.

[2] Australian Institute of Health and Welfare, The coding workforce shortfall, cat. no. HWL 46, AIHW, Canberra, 2010.

[3] R. Lawrance, From the office of the CEO, HIMAA Matters, 2(7) (2016), 2-3. 
[4] M. Kammermann, Census of Australian health libraries and self-described health librarians working in settings other than libraries final report, 2016,

https://www.alia.org.au/sites/default/files/CENSUS\%20of\%20Aus\%20Hlth\%20Libs\%20201214_Final\%20Report_2016.pdf

[5] Health Workforce Australia, Health information workforce report, 2013, <http://industry.gov.au/Officeof-the-Chief-Economist/SkilledOccupationList/Documents/2015Submissions/HIMAA-Attachment4.pdf $>$.

[6] K. Butler-Henderson, R. Lawrance, S. Low, N. Donnolley, \& J. Lee, Researching the health information workforce, Health Information Management - Interchange, vol. 6 (2) (2016), pp. 32-35.

[7] Health Information Management Association of Australia, Health information workforce summit 2016 summary and outline of agreed actions, 2016, http://himaa2.org.au/index.php?q=node/3199.

[8] K. Butler-Henderson, K. Gray, D. Greenfield, S. Low, C. Gilbert, A. Ritchie, M. Trujillo, V. Bennett, J. Brophy, \& L.K. Schaper, The development of a national census of the health information workforce: expert panel recommendations, Studies in Health Technology and Informatics, 239 (2017), 8-13.

[9] K. Butler-Henderson \& K. Gray, Health information workforce census website, 2018, http://www.utas.edu.au/business-and-economics/hiwcensus.

[10] K. Butler-Henderson \& K. Gray, Australia's health information workforce: census summary report 2018, University of Tasmania, 2018.

[11] Certified Health Informatician Australasia, Health informatics competencies framework, CHIA, 2013.

[12] Australian Bureau of Statistics, 6306.0 - employee earnings and hours May 2018, ABS Canberra, 2019. 